\title{
Human Impact on Lake Ecosystems (LIMPACS)
}

Although on a global scale lakes play only a minor role in hydrological and biogeochemical cycles, they have a special importance in many continental areas owing to their landscape value, their use as a natural resource (for water supply, recreation etc) and their value as natural ecosystems and centres of biodiversity. However, lakes are under increasing threat due to the separate, but often combined impact of:

- nutrient enrichment from domestic and agricultural pollution;

- acid deposition from fossil fuel combustion;

- salinisation from over extraction of freshwater;

- pollution from toxic metals, persistent organic pollutants and radionuclides;

- accelerated infill from catchment soil erosion;

- habitat disturbance from engineering projects;

- ecological disruption from species introductions and invasions.

- climate change from greenhouse gases;

In developing a global strategy for the protection or sustainable use of lakes it is crucial that we understand how lakes function on different time-scales in response to both natural forces and human impact and that we are able to predict how lake ecosystems will change in the future as stresses are altered.

The central theme of LIMPACS then is "understanding the past variability of lake ecosystems in order to predict better their future". It requires collaborative research between paleolimnologists and limnologists to bring together interdependent approaches for studying lake status, past, present and future. This interdependence involves modelling, measuring and reconstruction of lake attributes (Figure 1).

Modelling, especially process-based dynamic modelling, is needed to develop a system-level understanding of lake functioning and to make predictions of future status by scenario testing. Reconstruction, using paleolimnological techniques is needed to understand past variability on inter-annual and decadal time-scales and to provide model verification, whilst direct measurements from observation and experiment are needed to understand the nature of shortterm variability and to paramaterise and calibrate models and transfer functions. Where direct observations of an individual water body have taken place over several years to provide longer-term records of seasonal to decadal variability, time-series are created that can be used to evaluate the performance of both dynamic models and paleolimnological transfer functions (e.g.

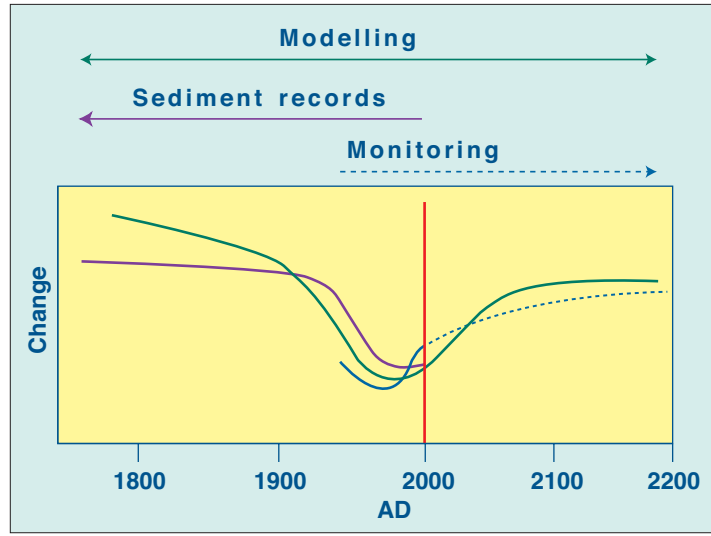

Figure 1: Limnological Change: The role of Sediment records, models and monitoring.

Figure 2). For some lake types, e.g. mountain lakes, such time-series are comparatively rare but as monitoring networks expand the data available for this purpose are increasing. Sites with long-term records will consequently play a key role in LIMPACS and one task within the programme will be to develop an inventory of such sites suitable for model testing.

\section{The Role of Paleolimnology}

Few ecosystems contain inbuilt archives of their history to match those of lakes. Over recent decades paleolimnologists have begun to exploit this archive

to provide unique insights into ecosystem change relevant to contemporary debates on lake functioning and human impact. LIMPACS will seek to develop this work further focussing especially on the need to:

- Disentangle natural forcing from human impact

- Identify the roles of different forcing variables

- Assess the response of lakes to known perturbation

- Define, where possible, lake naturalness

- Assess the current status of lakes in comparison to reference states

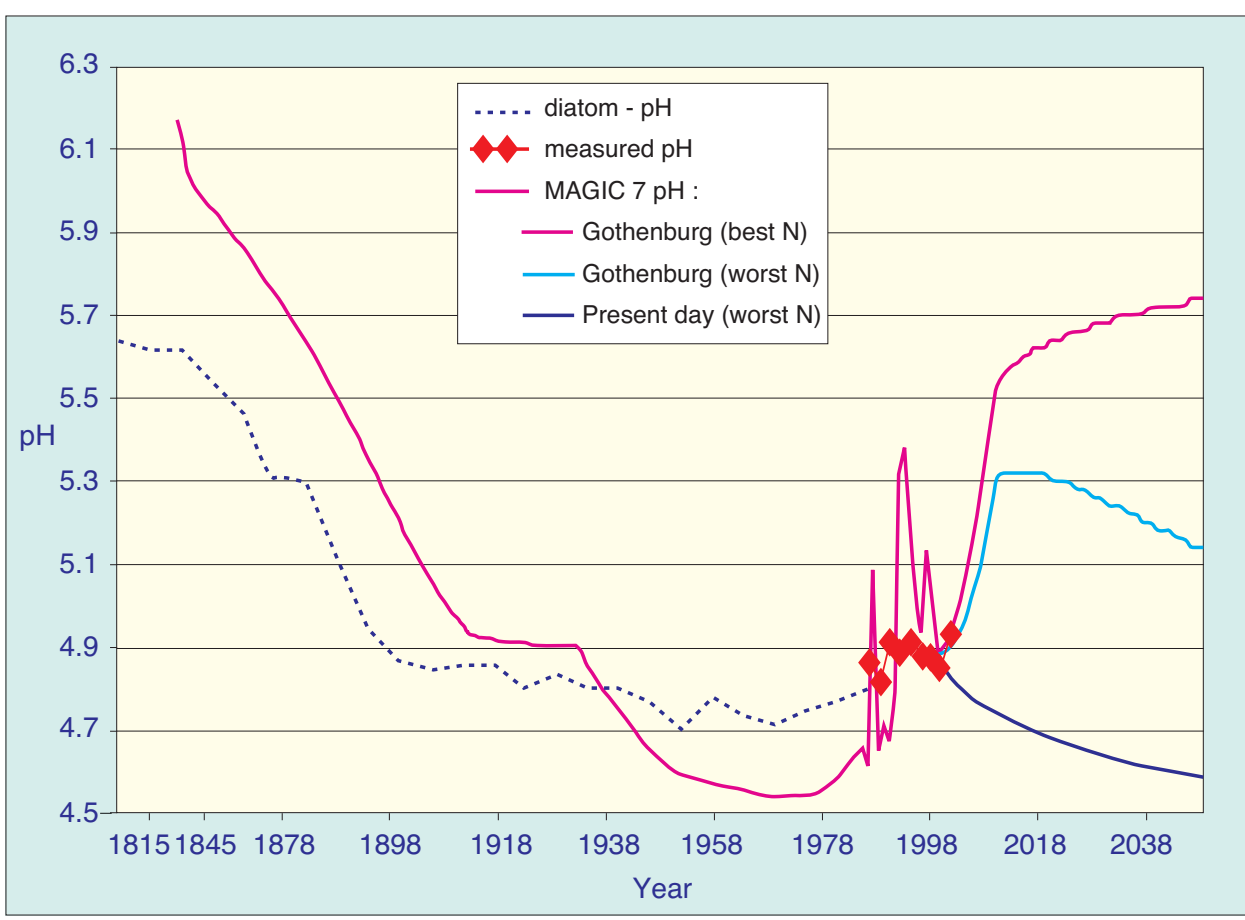

Figure 2: Combined plot of inferred, monitored and modelled $p H$ for the Round Loch of Glenhead from 1800-2050. Inferred $p H$ is based on a diatom- $p H$ transfer function, monitored $p H$ uses data from the UK Acid Waters Monitoring Network, and modelled $p H$ is from MAGIC, a dynamic catchment acidification model. The model forecasts are based on UK sulphur emission targets set out in the UNECE Second Sulphur Protocal (Gothenburg) and assume current emissions of nitrogen into the future. Worst and best case scenarios relate to uncertainty over the timing of $N$ saturation in catchment soils (Unpublished data from Jenkins, Monteith and Jones). 
- Define, where possible, sustainable ecological targets for lake restoration

- Identify and provide early warning of new threats

- Generate cause-effect hypotheses for ecological change, especially in relation to the impact of multiple stresses

- Evaluate steady-state and dynamic model output

Whilst useful methods for reconstruction based on high resolution core sampling, relatively accurate chronologies, multi-proxy analyses and reasonably robust transfer functions already exist, LIMPACS hopes to identify where critical further methodological improvements are needed. It will also encourage a move towards a more holistic paleoecological approach within paleolimnology that is concerned with ecosystem responses and interactions as well as environmental reconstruction. Entirely new techniques for dating and analysis may also be needed and it will be essential to explore GIS and model-based approaches for upscaling to regional and global scales. It will also be necessary to work closely with the LUCIFS and HITE communities especially in exploring relationships between lake change and lake catchment change.

\section{Progress so far}

LIMPACS is still in its formative stages. A steering group* of paleolimnologists, limnologists and modellers has been set up and a science implementation plan is being developed. The next step is to set up a series of working groups. It is envisaged that each will be concerned with processes associated with specific threats or stresses as follows:

- acidity, sulphur and nitrogen

- uvb radiation, dissolved organic carbon

- nutrient enrichment, phosphorus and nitrogen

(i) deep lakes, oxygen (ii) shallow lakes, trophic interactions

- salinity, ionic composition and hydrological change

- warming, stratification and mixing

- pollution, toxic metals and organics

- sediment infilling, catchment erosion

- introduced species

Further information is available on the LIMPACS web-page: www:// geog.ucl.ac.uk/ecrc/limpacs. Anyone interested in taking part in LIMPACS should contact Rick Battarbee or Cathy Stickley (c.stickley@ucl.ac.uk).

\section{Rick Battarbee}

Environmental Change Research Centre, University College London, UK

r.battarbee@ucl.ac.uk

* Steering group members are: John Anderson, John Smol, Brian Rippey, Peter Dillon, Colin Reynolds, Erik Jeppesen, Rick Battarbee, Dan Engstrom, Mike Binford, Peter Gell and Marten Scheffer.

\section{Ecosystem Processes and Human Dimensions - The Scope and Future Of HITE (Human Impacts on Terrestrial Ecosystems)}

\section{Introduction and Rationale}

Ecologists are increasingly aware that a complete understanding of ecosystems may require the observation and analysis of ecosystem functioning over relatively long time-scales. This may be seen from three perspectives. First, information about the causes, rates of change and direction of long term ecological trajectories may show how modern terrestrial ecosystems are conditioned by past interactions between human activities and the natural environment. Second, analysis of past ecosystem processes and rates of change may provide at least partial analogues for present and projected responses to human impact and climate change. Third, long ecological time-series may allow calibration and evaluation of predictive ecological models.

For these purposes, information about past ecosystems gained through direct observations, monitoring and measurement will often be either of insufficient length or not available. This limits the value of such an approach both for documenting and understanding the processes involved in terrestrial ecosystem change, as well as for developing and validating relevant models. The over-riding goal of HITE is therefore to further the use of environmental archives for documenting and understanding terrestrial ecosystem change through time; thereby improving the scientific basis for ensuring the security and enhancing the value of terrestrial ecosystems for the future. The scope must embrace not only human impacts but also climate variability, since the two interact. It must also be firmly rooted in our understanding of ecological principles and processes derived from studies of contemporary systems.

The initiative seeks to define and to promote research on key issues relating to human impact and natural environmental change. Paleo-ecological research has a long tradition, but paleo-ecological findings have often been under-exploited in terms of their input to our understanding of terrestrial ecosystems. Within the context of
PAGES, this reflects the extent to which research so far has laid stress on climate systems. In this type of formulation, paleo-ecological evidence is used almost exclusively as a basis for inferring climate by means of transfer functions of various kinds. This fails to accommodate paleo-ecology in its own right, that is to say, reconstructing the nature of past ecosystems through evidence independent of that used to infer climate change. Only by doing this will it be possible to understand, without recourse to circular argument, the complex of environmental factors and processes responsible for ecosystem development, modification, or demise. An additional impediment to a fuller development of paleo-ecology as we understand it has been the tendency for too many studies to use singly proxies (for example pollen analysis) as the sole basis for inferring past ecosystem change. Just as paleo-climate research has come to rely on a wide range of mutually constraining proxies, so must paleo-ecology learn to benefit from the 